\title{
Role of LDH levels in differentiating anemias
}

\author{
Noorin Zaidi', Rasha Zia Usmani ${ }^{2}$, Kshama Tiwari ${ }^{3}$, Sumaiya Irfan4, Syed Riaz Mehdi \\ ${ }^{1}$ Associate Professor, ${ }^{3,4}$ Assistant Professor, ${ }^{5}$ Professor, Department of Pathology, Eras Lucknow Medical College and Hospital, \\ Lucknow, ${ }^{2}$ Senior Resident, Department of Pathology, Government Medical College and Super Facility Hospital, Azamgarh
}

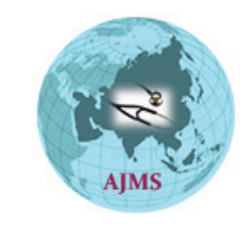

Background: There is a need to differentiate megaloblastic anemia from mixed deficiency anemia as both require different management protocols. With the acquisition of more information about them, tests such as serum vitamin estimation and Schilling test, were found to have their limitations. Hence there is a need to search newer diagnostic candidates to differentiate between megaloblastic anemia and mixed deficiency anemia. Aims and Objective: The current study was undertaken to find usefulness of serum Lactate Dehydrogenase (LDH) in differentiating megaloblastic anemia from mixed deficiency anemia. Materials and Methods: 100 patients were included in the study. Blood smears were stained and analysed. Complete blood counts were performed. Bone marrow examination was done, where needed. Biochemical tests were performed for estimation of vitamin B12, Folate and for LDH. Results: Out of the 100 cases 51 were diagnosed as megaloblastic anemia and 49 were diagnosed as mixed deficiency anemia. The LDH levels were significantly higher in cases of megaloblastic anemia as compared to mixed deficiency anemia. Conclusion: Serum LDH levels can be used in differentiating megaloblastic anemia from mixed deficiency anemia.

Keyword: Lactate dehydrogenase; Megaloblastic anemia; Mixed deficiency anemia

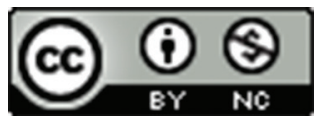

This work is licensed under a Creative Commons Attribution-NonCommercial 4.0 International License.

\section{INTRODUCTION}

Anaemia is defined by the World Health Organisation as haemoglobin $(\mathrm{Hb})<120 \mathrm{~g} / \mathrm{L}$ in women and $\mathrm{Hb}<130 \mathrm{~g} / \mathrm{L}$ in men. Anaemia is a recognized public health problem throughout the world. Almost every fourth person on the earth is anaemic. Most of the burden of anemia is attributed to nutritional deficiencies. ${ }^{1}$

The term 'nutritional anemia' encompasses all pathological conditions in which the blood hemoglobin concentration drops to an abnormally low level, due to a deficiency in one or several nutrients. The main nutrients involved in the synthesis of hemoglobin are iron, folic acid, and vitamin $\mathrm{B} 12$. Iron deficiency is the commonest cause of nutritional anemia worldwide while folic acid and/or B 12 deficiency is less widespread and is often observed with iron deficiency. ${ }^{2}$

For differential diagnosis, it is useful to classify the type of anemia based on the red cell indices which is calculated from red blood cell count, hemoglobin concentration, and hematocrit. The mean corpuscular volume (MCV) is calculated from hematocrit $(\%) \times 10 / \mathrm{RBC}$ count $(106 / \mu \mathrm{l})$, and macrocytic anemias are defined as MCV $>100 \mathrm{fl}$.

The cause of macrocytic anemia is classified into one of the following categories, megaloblastic or nonmegaloblastic whereby megaloblastic anemia is caused by deficiency or impairment of utilization of vitamin B12 or folate. ${ }^{3}$ The mean corpuscular $\mathrm{Hb}(\mathrm{MCH})$ and MCV distinguish macrocytic anemia from iron deficiency anemia, which is hypochromic and typically microcytic. Deficiencies of multiple nutrients or the use of certain medications can lead to a combination of iron deficiency anemia and macrocytosis, with resultant normocytic anemia. ${ }^{4}$

Iron deficiency anemia can be distinguished from other causes of microcytic and hypochromic anemia using iron studies $^{4}$ and a defined set of tests are used to distinguish megaloblastic from non megaloblastic anemias. ${ }^{3}$ 
Due to various nutrient deficiency mixed deficiency anemias generally exhibit dyserythropoiesis which may lead to a hemolytic picture. There is intramedullary destruction of red blood cells along with low reticulocyte count. ${ }^{5}$

At one time, the diagnosis of a deficiency of vitamin B12 or folate was considered to be relatively straight forward. As knowledge has accumulated, the limitations of such tests as serum vitamin level measurements and the Schilling test have become apparent and hence need for newer tests. ${ }^{6}$ One such candidate is serum Lactate Dehydrogenase (LDH).

Elevation of plasma lactate dehydrogenase concentration $(\mathrm{LDH})$ is known to occur in patients with megaloblastic anaemia. Gross elevation of serum Lactate dehydrogenase $(\mathrm{LDH})$ in megaloblastic anemia was first reported by Hess and Gehm back in 1955. ${ }^{7}$ Still LDH could not be popularized owing to difficulty in assessment. However, with the emergence of newer technology simplifying these assessments, a new interest has generated in identifying the usefulness of Serum LDH levels for differentiation of megaloblastic anemia from other nutritional anemias but there is still a lack of consensus regarding its clinical usefulness in the primary diagnosis of megaloblastic anemia. ${ }^{8-10}$

Hence we carried out a study to compare the LDH levels in megaloblastic anemia and mixed nutritional deficiency anemias and to assess the differentiating role of Serum LDH levels as a low-cost early diagnostic modality for identification of megaloblastic anemia.

\section{MATERIALS AND METHODS}

This was a comparative study carried out over a period of 18 months. All cases of megaloblastic anemia and mixed nutritional deficiency anemia were included in the study. Proper ethical permission had been taken and patient consent was also taken. Blood samples were taken in EDTA vials for complete blood counts and in plain vials for folate and vitamin B 12 estimation and for iron studies. Blood smears were stained using Leishman stain to study general blood picture.

Biochemical tests were done by Chemiluminescence method on VITROS-5600. Ferritin assessment was done using Orthoclinical Diagnostics kit, LOT number-1960 while Serum Iron assessment used Orthoclinical Diagnostics kit, LOT number-50307. Total Iron Binding Capacity assessment was done by Orthoclinical Diagnostics kit, LOT number-36787. Folate and Vitamin B12 estimation was done using Orthoclinical Diagnostics kit, LOT number-1860. Serum LDH estimation was done by Orthoclinical Diagnostics kit, LOT number-6352-8555.
Bone marrow aspiration, if needed, was done and slides stained by Giemsa stain.

Using the above mentioned test results patients were divided into two groups:

1) Mixed nutritional deficiency anemia- decreased levels of folate and/or vitamin B12 and deranged iron studies.

2) Megaloblastic anemia: decreased levels of folate and/ or vitamin B 12 with normal iron profile.

\section{RESULTS}

The present study was carried out to ascertain the usefulness of $\mathrm{LDH}$ in differentiating megaloblastic anemia from mixed nutritional deficiency anemia. A total of 100 patients were included in the study with 51 patients diagnosed as megaloblastic anemia and 49 diagnosed as mixed deficiency anemia. Table 1 summarizes the baseline characteristics of all the 100 cases whereas Table 2 compares the hematological, clinical and biochemical parameters of the megaloblastic and mixed nutritional anemia group.

These 100 patients comprised of 57 males and 43 females. The mean age of presentation was 34.69 years, 35.96 years for megaloblastic anemia and 33.37 years for mixed nutritional anemia.

Forty-seven $(92.2 \%)$ patients of megaloblastic anemia presented with tingling and numbness while 32 (71.4\%) among mixed nutritional anemia presented with the same and this was statistically significant. However other presenting symptoms like fatigue, weakness, pallor and icterus did not show any statistically significant difference.

Among hematological parameters, mean hemoglobin and RBC count were $9.29 \mathrm{gm} / \mathrm{dl}$ and 2.69 million cells/dl respectively, without any statistically significant difference between the two groups. Mean values of mean corpuscular volume (MCV) for megaloblastic anemia and mixed deficiency anemia were 106.13 and $97.7 \mathrm{fl}$ respectively and mean corpuscular hemoglobin (MCH) were 34.28 and $32 \mathrm{pg}$ respectively. The differences were statistically significant. However the mean values of mean corpuscular hemoglobin concentration (MCHC) for megaloblastic and mixed deficiency anemia were 33.1 and $32.6 \mathrm{~g} / \mathrm{dl}$ respectively and the difference was not statistically significant.

Among biochemical parameters, mean serum iron was $48.04 \mathrm{mcg} / \mathrm{dl}$ in the megaloblastic anemia group while it was $42.96 \mathrm{mcg} / \mathrm{dl}$ in the mixed nutritional anemia group, which is a significant difference. Mean TIBC was $258.0 \mathrm{mcg} / \mathrm{dl}$ in megaloblastic anemia cases while it as 


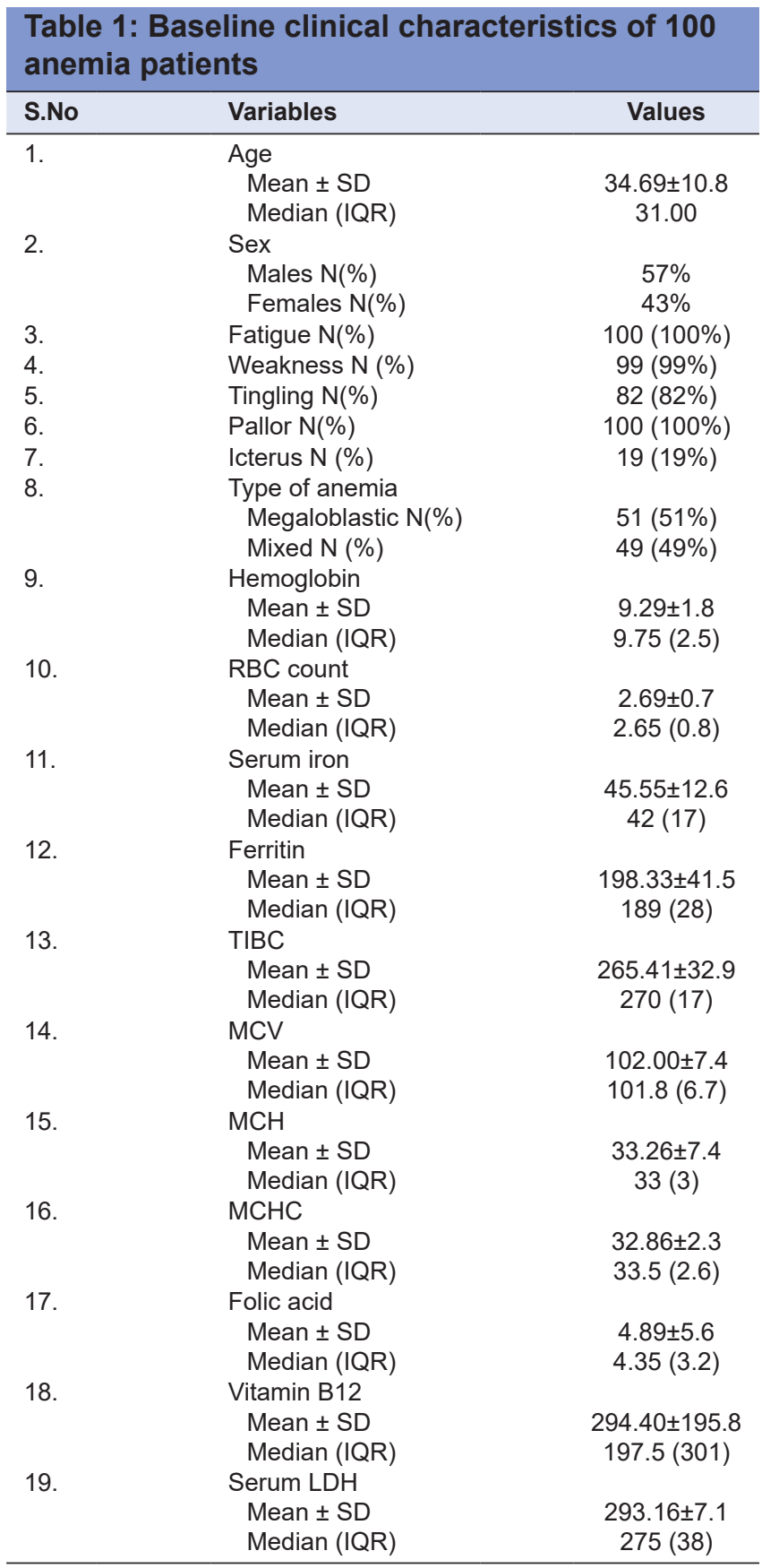

$272.53 \mathrm{mcg} / \mathrm{dl}$ among mixed nutritional anemia cases, which was again a statistically significant difference.

$\mathrm{LDH}$ was also found to be significantly higher in cases of megaloblastic anemia as compared to mixed nutritional anemia. The mean LDH value in former group was $320.86 \pm 15$ whereas in the latter group was $264.3 \pm 14$.

\section{DISCUSSION}

$\mathrm{LDH}$ is physiologically measurable in serum due to physiological cellular turnover and 5 isoenzymes are

\begin{tabular}{|c|c|c|c|}
\hline Variables & $\begin{array}{c}\text { Megaloblastic } \\
\quad \mathrm{N}=51\end{array}$ & $\begin{array}{l}\text { Mixed } \\
\mathrm{N}=49\end{array}$ & $P$ value \\
\hline \multicolumn{4}{|l|}{ Age } \\
\hline Mean \pm SD & $35.96 \pm 11.0$ & $33.37 \pm 10.7$ & 0.28 \\
\hline Median (IQR) & $38(18)$ & $30(17)$ & \\
\hline \multicolumn{4}{|l|}{ Sex } \\
\hline Males N (\%) & 27 (52.9\%) & $30(61.2 \%)$ & 0.114 \\
\hline Females N (\%) & $24(47.1 \%)$ & $19(38.8 \%)$ & \\
\hline Fatigue $\mathrm{N}(\%)$ & $51(100 \%)$ & $49(100 \%)$ & \\
\hline Weakness N (\%) & $50(98 \%)$ & $49(100 \%)$ & 0.51 \\
\hline Tingling N (\%) & $47(92.2 \%)$ & $32(71.4 \%)$ & 0.006 \\
\hline Pallor N (\%) & $51(100 \%)$ & $49(100 \%)$ & \\
\hline Icterus N (\%) & $12(23.5 \%)$ & $7(14.3 \%)$ & 0.103 \\
\hline \multicolumn{4}{|l|}{ Hemoglobin } \\
\hline Mean \pm SD & $9.36 \pm 1.7$ & $9.22 \pm 1.9$ & 0.1 \\
\hline Median (IQR) & $9.8(2.5)$ & $9.7(2.5)$ & \\
\hline \multicolumn{4}{|l|}{ RBC count } \\
\hline Mean \pm SD & $2.76 \pm 0.7$ & $2.63 \pm 0.7$ & 0.4 \\
\hline Median (IQR) & $2.7(0.9)$ & $2.6(0.8)$ & \\
\hline \multicolumn{4}{|l|}{ Serum iron } \\
\hline Mean \pm SD & $48.04 \pm 9.7$ & $42.96 \pm 14.6$ & $<0.05$ \\
\hline Median (IQR) & $45(14)$ & $37(15)$ & \\
\hline \multicolumn{4}{|l|}{ Ferritin } \\
\hline Mean \pm SD & $206.84 \pm 42.9$ & $189.47 \pm 38.4$ & 0.05 \\
\hline Median (IQR) & $192(25)$ & $188(29.5)$ & \\
\hline \multicolumn{4}{|l|}{ TIBC } \\
\hline Mean \pm SD & $258.0 \pm 40.6$ & $272.53 \pm 21.6$ & $<0.05$ \\
\hline Median (IQR) & $265(18)$ & $275(11)$ & \\
\hline \multicolumn{4}{|l|}{ MCV } \\
\hline Mean \pm SD & $106.13 \pm 5.8$ & $97.7 \pm 6.3$ & $<0.05$ \\
\hline Median (IQR) & $105(7.9)$ & $100(6.9)$ & \\
\hline \multicolumn{4}{|l|}{$\mathrm{MCH}$} \\
\hline Mean \pm SD & $34.28 \pm 3.5$ & $32 \pm 3.3$ & 0.004 \\
\hline Median (IQR) & $34(4)$ & $33(3)$ & \\
\hline \multicolumn{4}{|l|}{$\mathrm{MCHC}$} \\
\hline Mean \pm SD & $33.1 \pm 2.1$ & $32.6 \pm 2.5$ & 0.46 \\
\hline Median (IQR) & $33.5(2.5)$ & $33.5(2.9)$ & \\
\hline \multicolumn{4}{|l|}{ Folic acid } \\
\hline Mean \pm SD & $5.58 \pm 7.6$ & $4.17 \pm 1.8$ & 0.4 \\
\hline Median (IQR) & $4.5(3.2)$ & $3.1(3.1)$ & \\
\hline \multicolumn{4}{|l|}{ Vitamin B12 } \\
\hline Mean \pm SD & $255.69 \pm 154.6$ & $334.69 \pm 225.6$ & 0.06 \\
\hline Median (IQR) & $190(199)$ & $199(355)$ & \\
\hline \multicolumn{4}{|l|}{ Serum LDH } \\
\hline Mean \pm SD & $320.86 \pm 95.3$ & $264.3 \pm 14$ & $<0.05$ \\
\hline Median (IQR) & $295(34)$ & $260(10)$ & \\
\hline
\end{tabular}

present. ${ }^{11}$ Two isoenzymes of LDH, LDH-1 and LDH-2 are expressed in RBC. As decrease in red blood cell count is a distinct feature of anemia, ${ }^{12}$ hence a relationship between LDH expression and anemia could be anticipated. According to Heller \& Venger increased LDH activity combined with normal or slightly elevated transaminase values is typical of megaloblastic anemia. ${ }^{13}$ The mean patient age for megaloblastic anemia was 35.96 years whereas for mixed nutritional anemia was 33.37 years and we had taken only adult patients for our study i.e. above 18 years of age. There was a slight male preponderance as far as gender was concerned. These findings were quite 
similar to previous studies like the one by Pandya and Patel ${ }^{14}$ where maximum patients were in the age group 40-49 years and an overall male preponderance was seen.

Among hematological parameters, no statistically significant difference between the two groups was observed for mean hemoglobin, DLC, RBC and $\mathrm{MCHC}$, however, mean MCV and $\mathrm{MCH}$ of patients with megaloblastic anemia were significantly higher as compared to that of mixed nutritional deficiency anemia. According to a study done by Deepthi et al., ${ }^{15}$ on dimorphic anemia, due to concomitant iron deficiency and fragmentation of red blood cells MCV may be normal in nutritional anemia.

Serum vitamin B12 levels were significantly lower in megaloblastic anemia cases as compared to that in mixed nutritional deficiency anemia cases, however folate levels did not show any significant difference among the two groups. Cases with isolated folate deficiency were higher as compared to isolated B12 deficiency.

In present study, mean serum LDH levels were observed to be $321.78+96.08 \mathrm{IU} / \mathrm{dl}$ in megaloblastic anemia group as compared to $264.54+13.97 \mathrm{IU} / \mathrm{dl}$ in mixed nutritional deficiency anemia group. Statistically, mean values were significantly higher in megaloblastic anemia group as compared to that in mixed nutritional deficiency anemia group. As far as mean serum LDH levels in megaloblastic anemia are concerned, the findings in present study are similar to that observed in a number of previous studies (Table 3).

Mean serum LDH levels tend to be higher in cases of megaloblastic anemia. The increased LDH activity may be a result mainly of haemolysis, however it would require a much greater haemolytic activity than that found in megaloblastic anaemia. ${ }^{16}$ The findings of present study are similar to that observed by Gaikwad and Kadhav ${ }^{17}$ who observed mean serum LDH levels of megaloblastic anemia cases to be significantly higher as compared to that of hemolytic anemia and mixed anemia cases. They observed that though the mean $\mathrm{LDH}$ in mixed anemia cases were highly increased as compared to hemolytic anemia cases yet were lower as compared to megaloblastic anemia cases as observed in present study. These findings in turn suggest a more dominant role of serum B12 and folic acid levels in governing the LDH levels while iron deficiency seemed to play a regressive role.

Since our hospital caters to semi urban population of minority group, this study is first of its kind to be carried in such a population.

\section{CONCLUSION}

The present study aimed to utilize LDH as a discriminating marker between megaloblastic anemia and mixed nutritional deficiency anemia. It was found that serum LDH level

\begin{tabular}{|c|c|c|c|c|c|}
\hline SN & Author (Year) & Sample size & $\begin{array}{l}\text { Mean LDH levels } \\
\text { in Megaloblastic } \\
\text { anemia cases (IU/dl) }\end{array}$ & $\begin{array}{l}\text { Mean LDH levels } \\
\text { in comparative } \\
\text { group, if any }\end{array}$ & $\begin{array}{l}\text { Type of } \\
\text { comparative } \\
\text { group, if any }\end{array}$ \\
\hline 1. & Eivazi-Ziaei et al. $(2007)^{49}$ & 29 Cases & $\begin{array}{c}423 \mathrm{lU} / \mathrm{dl} \text { (Before } \\
\text { intervention) }\end{array}$ & $\begin{array}{l}78.3 \mathrm{IU} / \mathrm{dl} \text { (After } \\
\text { intervention) }\end{array}$ & $\begin{array}{l}\text { After } \\
\text { intervention }\end{array}$ \\
\hline 2. & $\begin{array}{l}\text { Chaudhari and Bindu } \\
(2015)^{15}\end{array}$ & $\begin{array}{l}50 \text { Cases, } 50 \\
\text { Controls }\end{array}$ & $239.6 \mathrm{IU} / \mathrm{dl}$ & $31.6 \mathrm{IU} / \mathrm{dl}$ & Healthy controls \\
\hline 3. & Gore et al. $(2015)^{50}$ & 42 Cases & $238.6 \mathrm{IU} / \mathrm{dl}$ & - & - \\
\hline 4. & Kannan et al. $(2016)^{51}$ & 38 Cases & $466.1 \mathrm{IU} / \mathrm{dl}$ & $68.3 \mathrm{IU} / \mathrm{dl}$ & $\begin{array}{l}62 \text { Macrocytic } \\
\text { non- } \\
\text { megaloblastic }\end{array}$ \\
\hline 5. & Sakhare et al. $(2017)^{52}$ & $\begin{array}{l}56 \text { Vitamin B12 } \\
\text { def. } \\
23 \text { FA def. } \\
\text { megaloblastic } \\
\text { anemia cases }\end{array}$ & $\begin{array}{l}384.4 \mathrm{IU} / \mathrm{dl} \\
406.6 \mathrm{IU} / \mathrm{dl}\end{array}$ & - & - \\
\hline 6. & $\begin{array}{l}\text { Gaikwad and Jadhav } \\
(2018)^{53}\end{array}$ & $\begin{array}{l}41 \text { Cases } \\
10+11 \text { Controls }\end{array}$ & $606.1 \mathrm{IU} / \mathrm{dl}$ & $\begin{array}{l}156.3 \mathrm{IU} / \mathrm{dl} \\
402.0 \mathrm{IU} / \mathrm{dl}\end{array}$ & $\begin{array}{l}\text { Hemolytic } \\
(n=10) \\
\text { Mixed deficiency } \\
(n=11)\end{array}$ \\
\hline 7. & Present study (2018) & $\begin{array}{l}50 \text { Megaloblastic } \\
50 \text { Mixed } \\
\text { nutritional } \\
\text { deficiency }\end{array}$ & $321.78 \mathrm{IU} / \mathrm{dl}$ & $264.54 \mathrm{IU} / \mathrm{dl}$ & $\begin{array}{l}\text { Mixed nutritional } \\
\text { deficiency }\end{array}$ \\
\hline
\end{tabular}


$>277.5$ IU/L can help in differentiating mixed nutritional deficiency and megaloblastic anemia with a high sensitivity as well as specificity ( $86 \%$ and $92 \%$ respectively). This can be useful for future studies and references.

\section{ACKNOWLEDGEMENT}

The authors would like to take this opportunity to thank the technical staff at Hospital Laboratory Services (HLS) where all the tests were carried out.

\section{REFERENCES}

1. de Benoist B, McLean E, Egil I, Cogswell M (Eds.). Worldwide prevalence of anaemia 1993-2005 - WHO Global Database on Anaemia. WHO-Centers for Disease Control and Prevention Atlanta

2. Kotecha PV. Nutritional anemia in young children with focus on Asia and India. Indian J Community Med. 2011; 36:8-16. https://doi.org/10.4103/0970-0218.80786

3. Nagao T and Hirokawa M. Diagnosis and treatment of macrocytic anemias in adults. J Gen Fam Med. 2017; 18:200-224 https://doi.org/10.1002/jgf2.31

4. Jimenez K, Kulnigg-Dabsch S and Gasche C. Management of Iron Deficiency Anemia. Gastroenterol Hepatol (NY). 2015; 11:241-250.

5. Sasidharan PK. B12 deficiency in India. Arch Med Health Sci 2017; 5:261-268.

https://doi.org/10.4103/amhs.amhs_121_17

6. Snow CF. Laboratory Diagnosis of Vitamin B12 and Folate Deficiency: A Guide for the Primary Care Physician. Arch Intern Med. 1999; 159:1289-1298.

https://doi.org/10.1001/archinte.159.12.1289

7. Hess B and Gehm E. Lactic acid dehydrogenase in the human blood. Klin Wochenschr. 1955; 33:91-93.
https://doi.org/10.1007/BF01473548

8. Chaudhari S and Bindu S. Correlation of Lactate Dehydrogenase in Megaloblastic Anemia. International Journal of Current Medical And Applied Sciences. 2015; 9: 28-32.

9. Jaswal TS, Mehta HC, Gupta V, Singh M and Singh S. Serum lactate dehydrogenase in diagnosis of megaloblastic anaemia. Indian J Pathol Microbiol. 2000; 43:325-329.

10. Eivazi-Ziaei J, Dastgiri $S$ and Sanaat Z. Estimation of the Diagnostic Value of Myeloperoxidase Index and Lactate Dehydrogenase in Megaloblastic Anaemia. Journal Clinical Diagnostic Research. 2007; 1(5): 380-384.

11. Barcellini W and Fattizzo B. Clinical Applications of Hemolytic Markers in the Differential Diagnosis and Management of Hemolytic Anemia. Dis Markers. 2015; 635-670. https://doi.org/10.1155/2015/635670

12. Nagababu E, Gulyani S, Earley CJ, Cutler RG, Mattson MP and Rifkind JM. Iron-deficiency anaemia enhances red blood cell oxidative stress. Free Radic Res. 2008; 42(9):824-829. https://doi.org/10.1080/10715760802459879

13. Heller $P$ and Venger $N$. Problems in the differentiation of the megaloblastic anemias. Med Clin N Amer. 1962; 46: 121-138. https://doi.org/10.1016/S0025-7125(16)33752-X

14. Pandya HP and Patel A. Clinical profile and response in patients with megaloblastic anemia. International Journal of Medical Science and Public Health. 2016; 5: 304-306. https://doi.org/10.5455/ijmsph.2016.13032015126

15. Deepthi A, Prasad CSBR and Raghavendra Prasad BN. Study of dimorphic anemia in adults with reference to basic etiology. Indian Journal of Pathology and Oncology. 2018; 5:61-66. https://doi.org/10.18231/2394-6792.2018.0012

16. Gronvall C. On the serum activity of lactic acid dehydrogenase and phosphohexoseisomerase in pernicious and hemolytic anemias. Scand J Clin Lab Invest.1961; 13: 29-36. https://doi.org/10.3109/00365516109137245

17. Gaikwad AL and Jadhav DS. Utility of serum lactate dehydrogenase in the diagnosis of megaloblastic anemia. Int $\mathrm{J}$ Res Med Sci. 2018; 6:3051-3056. https://doi.org/10.18203/2320-6012.jjrms20183643

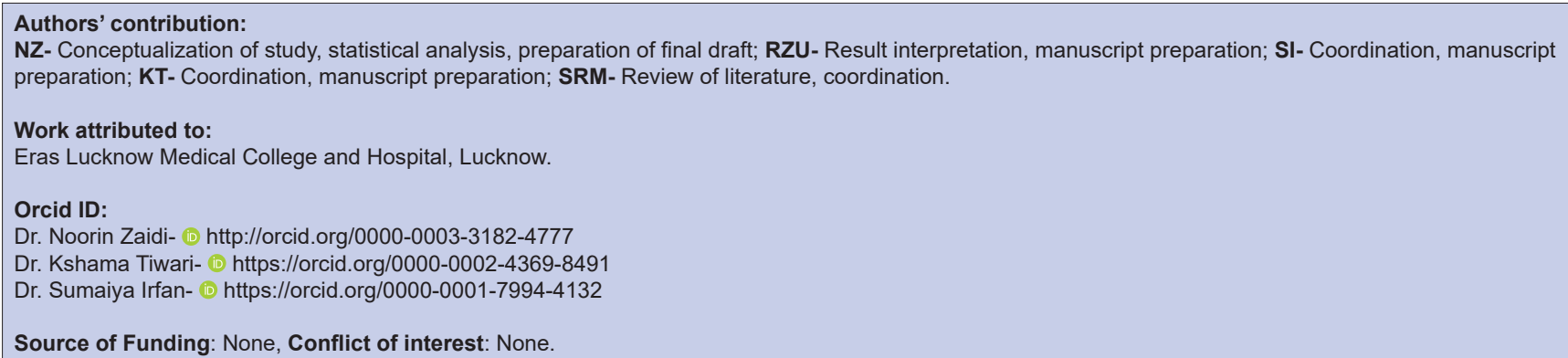

